\title{
A new beginning for Anatomical Science International $(A S I)$ with Springer: a message from the editor-in-chief
}

\author{
Kiyotaka Toshimori
}

Published online: 19 March 2009

(C) Japanese Association of Anatomists 2009

We are pleased to announce that Springer Japan now serves as the publisher of Anatomical Science International (ASI), formerly titled Kaibogaku Zasshi, the official English journal of the Japanese Association of Anatomists, beginning with this issue, in April 2009. In addition, I have the privilege of being named the fourth editor-in-chief, beginning on April 1, 2009.

$A S I$, launched in 2001, publishes quarterly issues containing original research and review articles dealing with morphological sciences in animals and humans. ASI is listed in many databases for scientific journals including PubMed and Web of Science as well as Journal Citation Reports. The impact factor of ASI was 1.161 for 2007 . Subscribers will find that $A S I$ has a new cover, with an artistic design for a new era of our society. No fee is charged for submissions; the major change in the new ASI regards fees for the use of color. Online publication of color illustrations is free of charge. For color used in the print version, authors are expected to make a contribution towards the extra costs per article, but there is no limitation on the extent to which color can be used in an article. This change thus encourages authors to submit more work that includes color illustrations. The online system Manuscript Central continues to support the submission and reviewing of manuscripts via the Internet. Another system, Online First, allows the quick online publication of articles before they appear in the print edition.

In the instructions for authors, there are details about Online First and about changes in the journal's Aims and

K. Toshimori $(\square)$

Professor and Chairman,

Department of Anatomy and Developmental Biology,

Chiba University Graduate School of Medicine, Chiba, Japan

e-mail: ktoshi@faculty.chiba-u.jp
Scope. In brief, papers on a wide range of morphological studies, including molecular, cellular, tissue and gross anatomical studies on normal and experimental animals and humans, are acceptable. Functional morphology, biochemical, physiological and behavioural studies are also considered as far as they contribute to the advancement of morphology. Also welcomed are reports of discoveries regarding the morphological effects of gene disruption, activation, or over-expression, as well as new observations made by new imaging techniques for real-time signalling processes, protein or gene expression in cells, tissues, or organ architecture. In addition, topics in anatomy education and other issues of general interest to readers are acceptable. Reports on techniques applicable to the abovementioned fields are also considered. ASI welcomes case reports on the human body from the point of view of gross anatomy. However, because of a shortage of available pages, only rare and very important cases, which make great contributions to analysing the morphogenesis of the human body, are considered. Miscellaneous items, including essays, book reviews, and commentaries are also published on approval of the Editorial Committee.

I sincerely hope that many excellent manuscripts from many countries are submitted to ASI. We promise to continue to grow as a truly international journal in collaboration with Springer.

Kiyotaka Toshimori, M.D. Editor-in-Chief, Anatomical Science International 